\title{
IPM Integrated crop management increases citrus growth and yields
}
J. Menge
a J.Morse
D. Hare
C.
A. Dodds
J. Meyer
T. Embleton
A. Strawn
$\square$
E. Pond
D. Atkin

The project was designed so that all combinations of all treatments could be analyzed. The objective was to incorporate current management practices for citrus production in order to identify practices that could maximize the yield or profitability of citrus production. By looking at interactions between various citrus technologies, we would be able to determine the "best practice." For example: Suppose heavy nitrogen levels gave maximum yields under normal conditions. What would happen under water rationing conditions? This is the type of question we wanted to answer, and thus far the project has given promising results.

\section{Project resources}

One reason for the project's success is that its personnel established it with great precision. They modified the statistical design three or four times to accommodate the plot design and the large number of treatments. The final design, a split-split factorial, although often criticized for having too few replications and two few treatment levels, has proved more than adequate to pinpoint differences in yield. Height, volume, and yield data were taken for all trees before the start of the experiment. This information proved invaluable in the covariance adjustment of subsequent yields. Similar results could have been attained with a less rigorous design, but one of the benefits of this project might be that one can now determine treatment interactions statistically with less effort in the field.

The staff replaced or revamped the irrigation system three times before declaring it adequate. Improved water filters were incorporated, and the system was monitored yearly to provide over $90 \%$ efficiency. Buffer rows of trees with identical irrigation levels $(80,100$, and $120 \%)$ bordered all data rows. Between these buffer rows, another row was treated with intermediate evapotranspiration values (90 or $110 \%$ ). This arrangement ensured that trees were not stealing water or being affected by irrigation from.neighboring rows. Other treatments were applied with similar precision.
The site for the experiment was a 22-acre parcel of 35-year-old parent Washington navel orange grown on rough lemon rootstock. The grove was in the heart of citrus country near Visalia, California. The owner, Robert McKellar, had expressed an interest in cooperating with UC on the project, and a formal lease agreement was drawn up. A packinghouse associated with McKellar Farms provided a great deal of assistance in packing and grading fruit. Citrus Specialist John Pehrson and Staff Research Associate Darwin Atkin, both based at Lindcove Field Station, were responsible for day-to-day activity in the plots. A committee led by John Menge directed the project. More than 30 university personnel have been associated with the project at one time or another. Selected personnel and their contributions to the project are described below.

John Menge, UC Riverside Department of Plant Pathology, examined root growth and root health in the project and directed the application of fungicides and nematicides. Joe Morse,UCRDepartment of Entomology, carried out extensive investigations on citrus thrips. Dan Hare, also of the UCR Department of Entomology, examined the effects of treatments on red mite populations and carried out the miticide spray program. Charles Coggins, UCRDepartment of Botany and PlantSciences, was responsible for evaluating fruit quality and directing the gibberellin sprays. Steve Post and Jewell Meyer, UCR Cooperative Extension, Soils and Environmental Sciences, designed, established, and monitored the irrigation system, and were responsible for gathering soil moisture data from neutron probes and tensiometers. Tom Embleton, UCR Department of Botany and Plant Science, and Wes Jarrell, Department of Soils and Environmental Sciences, were responsible for fertilization in the plot and for the analyses of leaves for mineral elements. Seymour Van Gundy, now Dean of the College of Natural and Agricultural SciencesatUCR, monitored the nematode populations from the plot. Allan Dodds, UCR Department of Plant Pathology, examined the viruses present in the plot. Mary Lu Arpaia, UCR Cooperative Extension, Department of Botany and Plant Sciences, evaluated the storage and postharvest characteristics of the fruit from the project. Eta Takele, UCR Cooperative Extension, Soiland Environmental Sciences, was the project's economist, and was responsible for determining and analyzing fruit grade and size. Carol Adams, UCR Cooperative Extension, Department of Statistics, proved invaluable in designing, sampling, analyzing, and interpreting results. Ann Strawn, UC IPM Program Analyst, and Elinor Pond, Staff Research Associate, Department of Plant Pathology, were responsible for analyzing and storing the tremendous quantities of data gathered from the project. The project is probably the best example of a truly integrated research approach. While the management headaches for such a project are many, the rewards have been enormous.

The project was funded by the Statewide IPM Project in 1984 for three years and has since received Citrus Advisory Board funding and Form $\mathrm{H}$ funding. The project is now in its seventh and final year.

\section{Results}

The project has provided insights into many areas of citrus production. While we cannot review all of the data here, several points can be made. Irrigation appears to have the largest effect on yield. The highest production level occurred at $120 \%$ of evapotranspiration demand of the trees. This result was surprising, since we felt that overirrigation would lead to root health problems by encouraging Phytophthora populations. To date this has not occurred, and the trees receiving $120 \%$ of evapotranspiration yielded $12 \%$ more fruit than the trees receiving $100 \%$ of evapotranspiration. Those trees receiving only $80 \%$ of evapotranspiration demand yielded only $3 \%$ less than those receiving $100 \%$ of evapotranspiration. While these figures may encourage growers who face watershortages, we should add that the trees receiving $80 \%$ of evapotranspiration are losing leaves and declining, and the fruit are smaller and of poorer quality. Nevertheless, citrus appears able to weather short periods of water stress with relative ease. Irrigation effects were uniform across the other variables.

The next biggest factor affecting yield is nitrogen. Medium nitrogen treatments resulted in fruit yields about $8 \%$ above those of the low-nitrogen treatments, and trees receiving the high-nitrogen treatments had yields $4 \%$ above those of the medium treatments. As with irrigation, the effects of nitrogen were consistent across the other variables of the study.

Fungicide-nematicide treatments for Phytophthora and nematodes showed the next strongest effect on yield. Treated trees 
produced $10 \%$ more fruit than untreated trees. Treatment for citrus red mite resulted in a 9\% increase in yield. In no case were statistically significant increases observed for every year, though the trends remained the same for all years.

All of the above treatments are beneficial, and they appear to be additive: with the right combinations, they can increase yields substantially. Alternatively, a farmer who makes a single mistake is not likely to see a big reduction in yield. Furthermore, farmers who are forced to water-stress their trees can make up for that in the short term by treating with fungicides, nematicides, or nitrogen.

Increased size in packout was noted in the fungicide-nematicide treatments, the $120 \%$ evapotranspiration treatments, and the gibberellin treatment. What's more, the packout results also appear to be additive. The size and packout increase dramatically when all three treatments are used. Mite sprays appear to reduce size and packout, probably because they reduce fruit drop.

Interactions observed in the experiment include: (1) nitrogen sprays appear to increase thrips scarring on fruit; (2) nitrogen sprays appear to reduce mite populations; (3) nitrogen sprays appear to reduce Phytophthora populations; and (4) fungicidenematicidetreatments and irrigation at $120 \%$ evapotranspiration can reduce crease, a rind disorder. Crease is thought to be caused by a deficiency of potassium. Fungicidenematicidetreatments resulted in more roots, while trees receiving $120 \%$ of evapotranspiration demand resulted in a larger wetted area for potassium uptake.

These are only a sample of the results for the McKellar project. The key to the project is not to obtain the highest yield, but to maximizenet income for the grower. During the project's final year, Agricultural Economist Eta Takele will try to estimate which treatments will be most efficient and lucrative for growers.

J. Menge is Professor and Plant Pathologist, J. Morse is Associate Professor and Associate Entomologist, D. Hare is Assistant Professor and Assistant Entomologist, C. Coggins is Professor and Plant Physiologist, J. Meyer is Extension Irrigation and Soils Specialist, T. Embleton is Professor and Horticulturist (Emeritus), S. Van Gundy is Dean of the College of Natural and Agricultural Sciences, A. Dodds is Professorand Plant Pathologist, M. L. Arpaia is Extension Subtropical Horticulturist, E. Takele is Extension Area Farm Management Specialist, C. Adams is Principal Statistician (Cooperative Extension), A. Strawn is Program Analyst (Entomology), and E. Pond is Staff Research Associate (Plant Pathology), all at UC Riverside; and J. Pehrson is Citrus Specialist and D. Atkin is Staff Research Associate, both at Lindcove Field Station, Exeter.

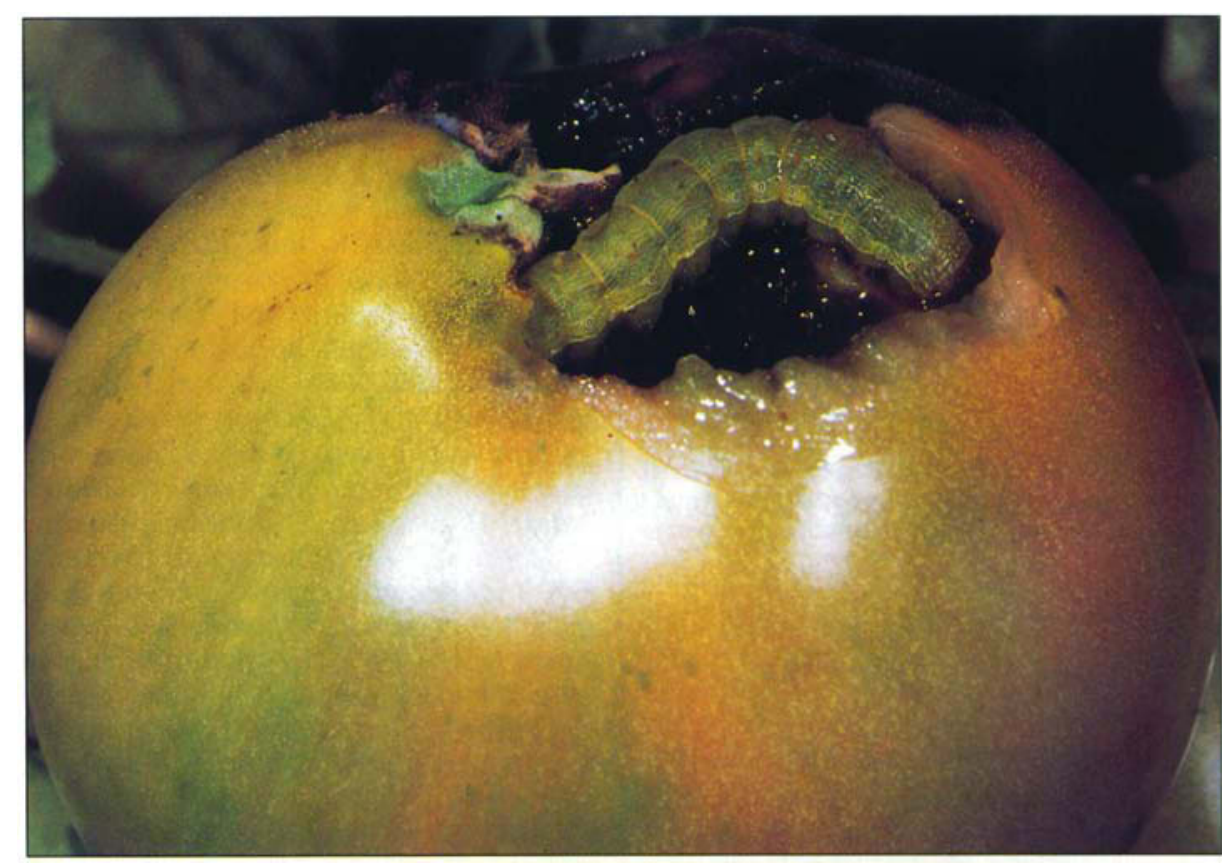

Tomato fruitworm (Heliothis zea) larvae attack the fruit of tomatoes and several other California crops, and can render them unmarketable.

\title{
IPM Monitoring tomato fruitworm eggs in processing tomatoes
}

\author{
Frank G. Zalom a Craig V. Weakley a Michael P. Hoffmann \\ L. T. Wilson a James I. Grieshop a Gene Miyao
}

\section{Research on egg distribution and treatment levels for the tomato fruitworm led to a set of monitoring guidelines, which were demon- strated in parts of the Sacramento Valley. Evaluation of this program documents grower adoption and an impact on insecticide use.}

The tomato fruitworm, Heliothis zea (Boddie), is among a group of Lepidoptera insects associated with processing tomato production in California. Heliothis zea is the most destructive insect pest in the Sacramento Valley. Historically, it has been the target of most of the insecticides applied to the crop. Growers who took no action to control the pest when it was present in large numbers risked exceeding state standards for damage, or more strict standards imposed by processors. Before this study, some Pest Control Advisers (PCAs) attempted to quantify their field monitoring by using damage estimates from randomly collected fruit. Less commonly, they shook plants over sheets to catch the larvae. Pesticide treatment was considered necessary when the damaged fruit in random fruit counts exceeded $0.25 \%$.

A series of studies was begun in 1981 to developan easy-to-use monitoring program with research-based damage thresholds. The 8-year process, which involved multiple actors, illustrates a valuable model for development, adoption, education, and evaluation to ensure the use of important agricultural innovations.

\section{Initial research}

In 1981, 36 small research plots were established in each of three growers' fields to compare four potential sampling methods. Two plants per plot were removed each week, and the number and location of all fruit, damaged fruit, fruitworm eggs, and larvae were recorded. This study revealed large differences in the average times required to perform each method and in their relative efficiencies. For example, picking 500 fruit from consecutive plants in a row and recording the number of fruit damaged took a worker 80 minutes. Shaking 20 plants 